\title{
BMJ Open Comparison of two anterior fusion methods in two-level cervical spondylosis myelopathy: a meta-analysis
}

\author{
Zhe-Yu Huang, Ai-Min Wu, Qing-Long Li, Tao Lei, Kang-Yi Wang, Hua-Zi Xu, \\ Wen-Fei Ni
}

To cite: Huang Z-Y, Wu A-M, Li Q-L, et al. Comparison of two anterior fusion methods in two-level cervical spondylosis myelopathy: a meta-analysis. BMJ Open 2014;4:e004581.

doi:10.1136/bmjopen-2013004581

- Prepublication history and additional material is available. To view please visit the journal (http://dx.doi.org/ 10.1136/bmjopen-2013004581)

Received 3 December 2013 Revised 23 June 2014 Accepted 24 June 2014

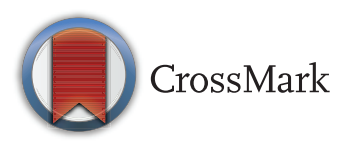

The Department of Orthopedics Surgery, Second Affiliated Hospital of

Wenzhou Medical University, Wenzhou, China

Correspondence to Dr Wen-Fei Ni; wenfeini@yeah.net

\section{ABSTRACT}

Objective: The aim of this study was to evaluate the efficacy and safety of anterior cervical corpectomy and fusion (ACCF) and anterior cervical discectomy and fusion (ACDF) for treating two-adjacent-level cervical spondylosis myelopathy (CSM).

Design: A meta-analysis of the two anterior fusion methods was conducted. The electronic databases of PubMed, the Cochrane Central Register of Controlled Trials, ScienceDirect, CNKI, WANFANG DATA and CQVIP were searched. Quality assessment of the included studies was evaluated using the Cochrane Risk of Bias Tool and the Methodological Index for Non-Randomised Studies criteria. Pooled risk ratios of dichotomous outcomes and standardised mean differences (SMDs) of continuous outcomes were generated. Using the $\chi^{2}$ and $\mathrm{I}^{2}$ tests, the statistical heterogeneity was assessed. Subgroup and sensitivity analyses were also performed.

Participants: Nine eligible trials with a total of 631 patients and a male-to-female ratio of 1.38:1 were included in this meta-analysis.

Inclusion criteria: Randomised controlled trials (RCTs) and non-randomised controlled trials that adopted ACCF and ACDF to treat two-adjacent-level CSM were included. Results: No significant differences were identified between the two groups regarding hospital stay, the Japanese Orthopaedic Association ( JOA) score, visual analogue scale (VAS) scores for neck and arm pain, total cervical range of motion (ROM), fusion ROM, fusion rate, adjacent-level ossification and complications, while ACDF had significantly less bleeding $(\mathrm{SMD}=1.14,95 \% \mathrm{Cl}(0.74$ to 1.53$)$ ); a shorter operation time (SMD $=1.13,95 \% \mathrm{Cl}$ (0.82 to 1.45)); greater cervical lordosis, total cervical $(\mathrm{SMD}=-2.95,95 \% \mathrm{Cl}(-4.79$ to -1.12$))$ and fused segment (SMD=-2.24, 95\% $\mathrm{Cl}(-3.31$ to -1.17$))$; higher segmental height $(\mathrm{SMD}=-0.68,95 \% \mathrm{Cl}(-1.03$ to $-0.34)$ ) and less graft subsidence (SMD $=0.40,95 \% \mathrm{Cl}$ (0.06 to 0.75$)$ ) compared to ACCF.

Conclusions: The results suggested that ACDF has more advantages compared to ACCF. However, additional highquality RCTs and a longer follow-up duration are needed.

\section{INTRODUCTION}

Cervical spondylosis is a common disease and a progressive degenerative process of the

\section{Strengths and limitations of this study}

- According to our study, anterior cervical corpectomy and fusion (ACCF) and anterior cervical discectomy and fusion (ACDF) are effective and safe for treating cervical spondylosis myelopathy.

- ACDF has more advantages than ACCF in some aspects.

- The trials included in our study are not highquality randomised controlled trials and do not have a long enough follow-up duration.

- The number of studies used in the meta-analysis is small (nine studies). In fact, for most of the outcomes, fewer than five studies were used in the meta-analyses.

- The pathological processes of patients are not always the same.

cervical spine that results in loss of disc height and formation of osteophytes. When it develops into cervical spondylosis myelopathy (CSM), motion abnormalities and sensory disturbances will follow, resulting in a reduced quality of life for the patients. ${ }^{1}$ Surgical intervention is recommended for these patients with severe symptoms. ${ }^{2}$

The choice between an anterior, posterior or combined approach for decompression is based primarily on (1) the sagittal alignment of the spinal column, (2) the extent of disease, (3) the location of the abnormal compression, (4) the presence of preoperative neck pain and (5) previous operations. ${ }^{2}$

Shamji $e t a l^{3}$ and Jiang $e t a l^{t}$ have reviewed the efficacy and safety of anterior procedures for patients with multilevel CSM, covering patients with two-adjacent-level CSM. Furthermore, the work by Chang et a $\bar{p}$ supports that anterior cervical discectomy and fusion (ACDF) is the treatment of choice for cervical disc herniation and spondylotic radiculopathy or myelopathy. In addition, Lu et at have shown that anterior cervical corpectomy and fusion (ACCF) is an effective surgical procedure for the treatment of multilevel cervical myelopathy because it can 
remove almost all osteophytes, discs and ossification of posterior longitudinal ligament pathology that cause spinal cord compression. Yonenobu et $a l^{7}$ and Kawakami et al have shown that ACDF and ACCF are widely used anterior methods for CSM, especially with two levels. Although patients with two-adjacent-level CSM are often seen in clinical practice, controversies still exist between ACCF and ACDF for treating these patients. Therefore, the aim of this meta-analysis was to compare the efficacy and safety of ACCF and ACDF for patients with two-adjacent-level CSM by assessing the perioperative, clinical and radiological outcomes as well as complications.

\section{MATERIALS AND METHODS}

\section{Search strategy}

The electronic databases including PubMed (1966-2013), the Cochrane Central Register of Controlled Trials (Issue 9, 2013), ScienceDirect (1985-2013), CNKI (1996-2013), WANFANG DATA (1997-2013) and CQVIP (1996-2013) were searched. The keywords used for the search were as follows: 'cervical spondylosis myelopathy,' 'anterior cervical discectomy and fusion,' 'anterior cervical corpectomy and fusion,' 'two level(s)' and 'single-level.'

\section{Eligibility criteria}

All comparative studies that adopted ACCF and ACDF to treat two-adjacent-level cervical spondylosis were identified, and the reference lists of identified articles were searched to identify other potentially eligible studies. Criteria for inclusion were as follows: (1) ACCF with titanium mesh, cage or autologous ilium bone grafting; ACDF with interbody cage devices or autologous ilium bone grafting; and the two surgeries used anterior cervical plate and screw fixation. (2) All patients included had a confirmed CSM at two adjacent segments, and surgical intervention was recommended. (3) The trials were followed up for more than 12 months.

Criteria for exclusion were as follows: (1) The studies did not meet the inclusion criteria. (2) The intraoperative outcome data (length of hospital stay, amount of bleeding and operation time), clinical outcomes (Japanese Orthopaedic Association (JOA) score and visual analogue scale (VAS) score for neck and arm pain), radiological outcomes (cervical lordosis for total cervical and fused segments, total cervical range of motion (ROM), segmental ROM, graft collapse, segmental height, fusion rate and degeneration of the adjacent level) or complications (short-term and long-term complications) were not reported. (3) The number of samples was less than 30 cases. (4) The patients evaluated were treated at the same hospital.

\section{Data extraction}

Two reviewers independently extracted the data using a standardised form, which covered the following items: (1) basic characteristics, including the year of publication, study design, inclusion/exclusion criteria, age, sex, enrolled number and follow-up rate; (2) intraoperative outcomes, consisting of length of hospital stay, amount of bleeding and operation time; (3) clinical outcomes, including JOA score and VAS score for neck and arm pain; (4) radiological outcomes, such as cervical lordosis for total cervical and fused segments, total cervical ROM, segmental ROM, graft collapse, segmental height, fusion rate, degeneration of the adjacent level and (5) complications, including short-term and long-term complications.

\section{Risk of bias assessment}

Two reviewers independently evaluated the quality of the included studies. Three randomised studies ${ }^{9-11}$ were assessed with the Cochrane Handbook for Systematic Review of Interventions, and six non-randomised studies $^{12-17}$ were evaluated according to the methodological index for non-randomised studies (MINORS) criteria, an established method for evaluating non-RCTs. ${ }^{18}$

\section{Statistical analysis}

All meta-analyses were performed with Review Manager 5.2 software (Cochrane Collaboration, Oxford, UK). For continuous outcomes, means and SDs were pooled to generate a standardised mean difference (SMD) and 95\% CIs were generated. According to the study by Kim et $a l,{ }^{17}$ a formula was used to obtain a combined mean and SD. ${ }^{19}$ For dichotomous outcomes, the risk ratio (RR) and $95 \%$ CI were assessed. A probability of $\mathrm{p}<0.05$ was considered to be statistically significant. Assessment for statistical heterogeneity was calculated using the $\chi^{2}$ and $\mathrm{I}^{2}$ tests. When the test for heterogeneity was $\mathrm{p}<0.1$ or $\mathrm{I}^{2}>50 \%$, the data were considered very heterogeneous. The source of heterogeneity was investigated by subgroup analysis and sensitivity analysis. A fixed effects model was used for homogeneous data, and a random effects model was used for data with high heterogeneity. As for the data with significant methodological heterogeneity, sensitivity analysis was adopted to find the source of the heterogeneity. With regard to the data with significant clinical heterogeneity, subgroup analyses were applied to identify the source of the heterogeneity.

\section{RESULTS}

\section{Literature search}

A total of 606 potential reports were retrieved with the search strategy (figure 1). Of these, 597 reports were excluded because they did not fit our inclusion criteria. No additional studies were obtained after the reference review. Finally, nine studies were selected and analysed..$^{9-17}$

\section{Risk of bias assessment}

For three randomised studies, ${ }^{9-11}$ two studies were RCTs, ${ }^{9} 11$ one of which did not provide information regarding allocation concealment. One study was a 
Figure 1 The search strategy for our meta-analysis and reasons for exclusion.

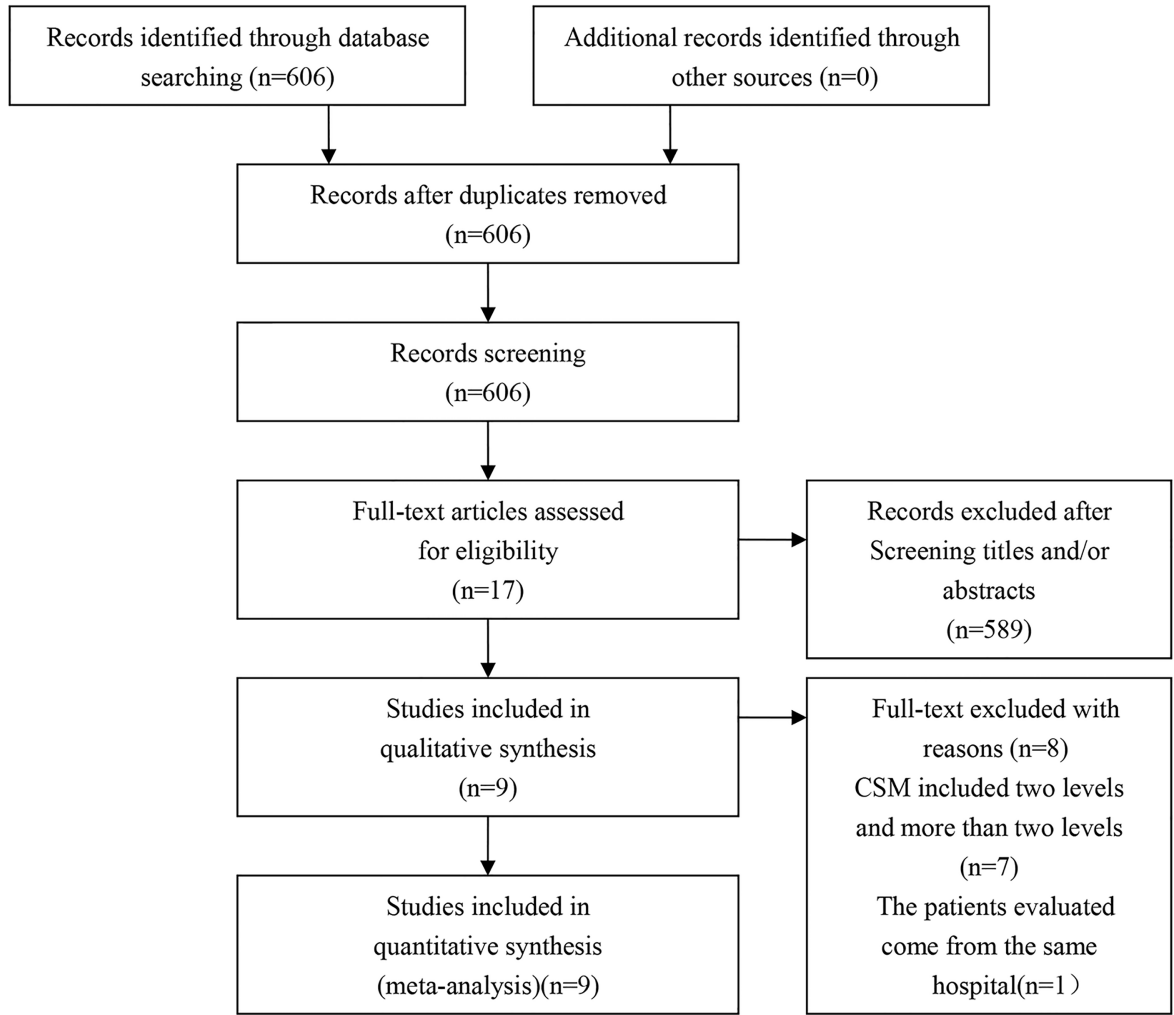

quasi-RCT, in which patients were allocated according to their sequence of hospitalisation. ${ }^{10}$ Owing to the informed consent rights between patients and doctors, it was impossible to blind all participants and personnel. None of these three studies reported blinding of outcome assessment. No patients were lost to follow-up, except for eight patients who were excluded from the study by Liu et $a l^{11}$ due to missing data. Thus, there was a low risk of bias due to incomplete outcome data. In these three trials, the outcomes were provided in detail and there was a low risk of bias due to selective reporting. Owing to insufficient information to assess whether an important risk of bias existed in a number of trials, it was hypothesised that all trials had an unclear risk of bias towards other potential sources of bias. The methodological quality assessment is summarised in table 1. For six non-randomised studies, ${ }^{12-17}$ according to the modified MINORS criteria, ${ }^{18}$ none of them reported an unbiased assessment of the study end point or a prospective calculation of the study size. With regard to the prospective collection of data, three studies did not reported the follow-up rate. ${ }^{14}$ The other eight items were all specifically reported. In summary, scores ranged from 16 to 18 , with a median value of 16.5 . The methodological quality assessment is summarised in table 2.

\section{Demographic characteristics}

The demographic characteristics of the patients included in the selected studies are presented in table 3 . A total of 631 patients, with a male-to-female ratio of 1.38:1, were included. Of these, 270 underwent ACCF procedures and 361 were treated by the ACDF approach; the two surgeries used various grafts, including autografts, allografts and cage and/or plate systems. The mean age of the patients was 55.1 years. The average duration of follow-up ranged from 18.9 to 43.2 months. Statistically similar baseline characteristics were observed between the ACCF and ACDF groups (table 4). report the relevant information. ${ }^{13} 1517$ Only one study

Table 1 Risk of bias assessment of randomised studies

\begin{tabular}{|c|c|c|c|}
\hline Risk of bias assessment & Oh et af & Yu et $a 1^{10}$ & Liu et $a I^{11}$ \\
\hline Random sequence generation & Unclear risk & High risk & Low risk \\
\hline Allocation concealment & Unclear risk & Unclear risk & Unclear risk \\
\hline Blinding of participants and personnel & High risk & High risk & High risk \\
\hline Blinding of outcome assessment & Unclear risk & Unclear risk & Unclear risk \\
\hline Incomplete outcome data & Low risk & Low risk & Low risk \\
\hline Selective reporting & Low risk & Low risk & Low risk \\
\hline Other sources of bias & Unclear risk & Unclear risk & Unclear risk \\
\hline
\end{tabular}


Table 2 Quality assessment of non-randomised studies

\begin{tabular}{|c|c|c|c|c|c|c|}
\hline $\begin{array}{l}\text { Methodological item for } \\
\text { non-randomised studies }\end{array}$ & $\begin{array}{l}\text { Park } \\
\text { et } a I^{12}\end{array}$ & $\begin{array}{l}\text { Wang } \\
\text { et } a l^{13}\end{array}$ & $\begin{array}{l}\text { Burkhardt } \\
\text { et } a^{14}\end{array}$ & $\begin{array}{l}\text { Yu } \\
\text { et } a I^{15}\end{array}$ & $\begin{array}{l}\text { Jia } \\
\text { et } a l^{16}\end{array}$ & $\begin{array}{l}\text { Kim } \\
\text { et } \mathrm{al}^{17}\end{array}$ \\
\hline 1. A clearly stated aim & 2 & 2 & 2 & 2 & 2 & 2 \\
\hline 2. Inclusion of consecutive patients & 2 & 2 & 2 & 2 & 2 & 2 \\
\hline 3. Prospective collection of data & 2 & 0 & 2 & 0 & 2 & 0 \\
\hline 4. End points appropriate to the aim of the study & 2 & 2 & 2 & 2 & 2 & 2 \\
\hline 5. Unbiased assessment of the study end point & 0 & 0 & 0 & 0 & 0 & 0 \\
\hline 6. Follow-up period appropriate to the aim of the study & 2 & 2 & 2 & 2 & 2 & 2 \\
\hline 7. Loss to follow-up less than $5 \%$ & 0 & 0 & 1 & 0 & 0 & 0 \\
\hline 8. Prospective calculation of the study size & 0 & 0 & 0 & 0 & 0 & 0 \\
\hline 9. An adequate control group & 2 & 2 & 2 & 2 & 2 & 2 \\
\hline 10. Contemporary groups & 2 & 2 & 2 & 2 & 2 & 2 \\
\hline 11. Baseline equivalence of groups & 2 & 2 & 2 & 2 & 2 & 2 \\
\hline 12. Adequate statistical analyses & 2 & 2 & 2 & 2 & 2 & 2 \\
\hline
\end{tabular}

\section{Hospital stay}

Details regarding hospital stay were available in three papers (see online supplementary table S1), ${ }^{9} 1116$ and statistical heterogeneity was absent in these studies $\left(\mathrm{I}^{2}=0 \% ; \mathrm{p}=0.69\right)$. The pooled estimate revealed a statistically insignificant difference $(\mathrm{SMD}=0.18,95 \%$ CI $(-0.15$ to 0.51 ), $\mathrm{p}=0.28$ ) (figure 2).

\section{Bleeding amount}

Relevant data regarding the bleeding amount were documented in four articles (see online supplementary table S1), ${ }^{9-11} 16$ and all the trials showed that the ACDF approach had significantly reduced intraoperative bleeding amounts compared to the ACCF procedure. Pooling of relevant data also showed a statistically significant difference between the two groups ( $\mathrm{SMD}=1.14,95 \%$ CI (0.74 to 1.53$), p=0.002)$. Significant heterogeneity was detected $\left(\mathrm{I}^{2}=89 \%\right.$; $\left.\mathrm{p}<0.00001\right)$ (figure $\left.2 \mathrm{~B}\right)$. In addition, sensitivity analysis confirmed the stability of bleeding amount outcomes (see online supplementary figure S1).

\section{Operation time}

Four trials reported a significantly shorter surgical time in the ACDF group compared to the ACCF group (see online supplementary table S1) ${ }^{9-11} 16$ Overall, the SMD was 1.13 (95\% CI (0.82 to 1.45$), \mathrm{p}<0.00001$ ) in favour of the ACDF group. There was obvious evidence of statistically significant heterogeneity $\left(\mathrm{I}^{2}=54 \% ; \mathrm{p}=0.009\right)$, according to the subgroup analysis (figure 3). Furthermore, sensitivity analysis confirmed the stability of operation time outcomes (see online supplementary figure S2).

\section{Japanese Orthopaedic Association}

Three studies reported the JOA score (see online supplementary table S2), ${ }^{9}{ }^{11}{ }^{16}$ and the pooled estimate revealed a statistically insignificant difference $(\mathrm{SMD}=0.14,95 \%$ CI $(-0.19$ to 0.47$), \mathrm{p}=0.41)$, with low heterogeneity $\left(\mathrm{I}^{2}=12 \%\right)$ (figure $\left.4 \mathrm{~A}\right)$.

\section{Neck VAS}

Three studies reported a postoperative neck VAS score (see online supplementary table S2), ${ }^{9}{ }^{14}{ }^{16}$ and the pooled data from the two relevant studies did not reveal any significant difference $(\mathrm{SMD}=0.13,95 \%$ CI $(-0.15$ to $0.41), \quad \mathrm{p}=0.36)$, with low heterogeneity $\left(\mathrm{I}^{2}=45 \%\right)$ (figure 4B).

\section{Arm VAS}

Relevant VAS data were documented in three articles (see online supplementary table S2). ${ }^{9} 1416$ There was no significant difference between the two treatment groups ( $\mathrm{SMD}=-0.15$, 95\%CI ( -0.43 to 0.13$) ; \mathrm{p}=0.28)$, with low heterogeneity $\left(\mathrm{I}^{2}=4 \%\right.$; figure $\left.4 \mathrm{C}\right)$.

\section{C2-C7 Cobb}

Five studies reported the C2-C7 Cobb at the final follow-up (see online supplementary table S3a) $;^{9} 12141617$ the available data demonstrated low heterogeneity $\left(\mathrm{I}^{2}=8 \%\right)$, and the ACCF group had a significantly lower Cobb than the ACDF group $(\mathrm{SMD}=-0.32$, $95 \%$ CI $(-0.53$ to -0.10$), \mathrm{p}=0.004$; figure $5 \mathrm{~A})$.

\section{Fusion Cobb}

Three studies reported the fusion Cobb at the final follow-up (see online supplementary table S3a); ${ }^{11} 1215$ the available data demonstrated no heterogeneity $\left(\mathrm{I}^{2}=0 \%\right)$, and the ACCF group had a significantly lower Cobb than the ACDF group $(\mathrm{SMD}=-0.50,95 \%$ CI $(-0.75$ to -0.24$), \mathrm{p}=0.0001$; figure $5 \mathrm{~B})$.

\section{Total cervical ROM}

Two studies reported the total cervical ROM data at the final follow-up (see online supplementary table S3b), ${ }^{9} 16$ and the other two studies demonstrated that there was no significant difference in total cervical ROM between the two groups $(\mathrm{SMD}=-0.02,95 \%$ CI $(-0.42$ to 0.37$)$, $\mathrm{p}=0.90)$, with no heterogeneity $\left(\mathrm{I}^{2}=0 \%\right.$; figure $\left.5 \mathrm{C}\right)$. 


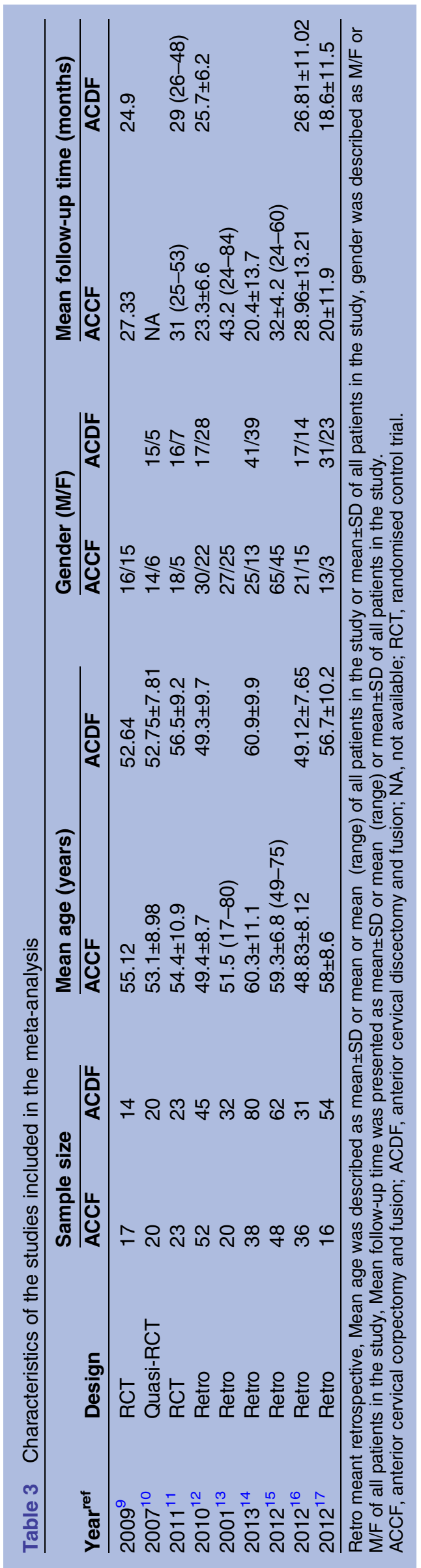

Fusion ROM

Two studies reported fusion ROM at the last follow-up (see online supplementary table S3b), ${ }^{916}$ and there was no significant difference in fusion ROM between the two groups $(\mathrm{SMD}=-0.05,95 \%$ CI $(-0.45$ to 0.35$)$, $\mathrm{p}=0.80)$, with low heterogeneity $\left(\mathrm{I}^{2}=20 \%\right.$; figure $\left.5 \mathrm{D}\right)$.

\section{Fused segment height}

Five studies reported the fused segment height data at the final follow-up (see online supplementary table S3b) ${ }^{9} 11141617$; however, data from three studies were excluded from this analysis because of the different methods used to measure the fused segment height. ${ }^{11} 1617$ The pooled results demonstrated that the ACCF group had a significantly lower fused segment height than the ACDF group ( $\mathrm{SMD}=-0.68,95 \%$ CI $(-1.03$ to -0.34$)$ ), with high heterogeneity $\left(I^{2}=76 \%\right.$; figure $\left.6 \mathrm{~A}\right)$.

\section{Graft collapse}

Two studies reported graft collapse at the last follow-up (see online supplementary table S3c), ${ }^{12}{ }^{15}$ showing that there was a significant reduction in graft collapse for the ACDF group $(\mathrm{SMD}=0.40,95 \%$ CI $(0.06$ to 0.75$)$, $\mathrm{p}=0.02)$, with moderate heterogeneity $\left(\mathrm{I}^{2}=68 \%\right.$; figure $6 \mathrm{~B})$. No significant clinical heterogeneity or methodological heterogeneity was found; however, statistical heterogeneity most likely exists, so the data from the two studies were pooled.

\section{Fusion rate}

Six studies reported the fusion rate at the last follow-up (see online supplementary table S3c), ${ }^{9}{ }^{10}{ }^{14-17}$ and there was no significant difference in the fusion rate between the two groups ( $R R=1.00,95 \%$ CI (0.97 to 1.04$), p=0.79$ ), with no heterogeneity $\left(\mathrm{I}^{2}=0 \%\right.$; figure $\left.7 \mathrm{~A}\right)$.

\section{Degeneration}

Three studies reported degeneration of the level adjacent to the fusion (see online supplementary table S3c), ${ }^{9} 1415$ showing that there was no significant difference in degeneration of the level adjacent to the fusion between the two groups ( $\mathrm{RR}=1.31,95 \%$ CI (0.44 to 3.93), $\mathrm{p}=0.63)$, with no heterogeneity $\left(\mathrm{I}^{2}=0 \%\right.$; figure $\left.7 \mathrm{~B}\right)$.

\section{Complications}

Data regarding complications were provided in eight studies (see online supplementary table S4) ${ }^{9-11} \quad 13-17$ There was no significant difference between the ACCF and ACDF groups according to individual and pooled data $(R R=1.25,95 \% \mathrm{CI}=(0.74$ to 2.13$) ; \mathrm{p}=0.40)$. Statistical heterogeneity was absent in these studies $\left(\mathrm{I}^{2}=0 \%\right.$; $\mathrm{p}=0.52$; figure $7 \mathrm{C}$ ).

\section{DISCUSSION}

Although most studies included in this analysis reported consistent results, ${ }^{9-17}$ the pooled estimates should be explained with caution. With regard to the operative 
Table 4 Comparison of baseline characteristics between the ACCF and ACDF groups

\begin{tabular}{|c|c|c|c|c|c|c|c|c|c|}
\hline Characteristic & $\begin{array}{l}\text { Oh } \\
\text { et } a \rho^{\rho}\end{array}$ & $\begin{array}{l}\text { Park et } \\
a I^{12}\end{array}$ & $\begin{array}{l}\text { Wang } \\
\text { et } a I^{13}\end{array}$ & $\begin{array}{l}\text { Burkhardt } \\
\text { et } a l^{14}\end{array}$ & $\begin{array}{l}\text { Yu } \\
\text { et } a I^{15}\end{array}$ & $\begin{array}{l}\text { Yu } \\
\text { et } a I^{10}\end{array}$ & $\begin{array}{l}\text { Jia } \\
\text { et } a l^{16}\end{array}$ & $\begin{array}{l}\text { Liu } \\
\text { et } a I^{11}\end{array}$ & $\begin{array}{l}\text { Kim } \\
\text { et } a I^{17}\end{array}$ \\
\hline Mean age & * & * & * & * & * & * & * & * & * \\
\hline Gender & * & * & * & * & * & * & * & * & * \\
\hline Follow-up & * & * & * & * & * & * & * & * & * \\
\hline Preoperative JOA & * & NA & NA & NA & NA & * & * & * & NA \\
\hline Preoperative neck VAS & * & NA & NA & * & NA & NA & * & NA & NA \\
\hline Preoperative arm VAS & * & NA & NA & * & NA & NA & * & NA & NA \\
\hline $\begin{array}{l}\text { Preoperative sagittal } \\
\text { alignment }\end{array}$ & NA & * & NA & NA & * & NA & NA & NA & NA \\
\hline Preoperative C2-C7 Cobb & * & * & NA & * & NA & NA & * & NA & * \\
\hline $\begin{array}{l}\text { Preoperative fused } \\
\text { segment height }\end{array}$ & * & NA & NA & * & NA & NA & NA & * & * \\
\hline $\begin{array}{l}\text { Preoperative total cervical } \\
\text { ROM }\end{array}$ & * & NA & NA & NA & NA & NA & 0.02 & NA & NA \\
\hline $\begin{array}{l}\text { Preoperative fused } \\
\text { segment ROM }\end{array}$ & * & NA & NA & NA & NA & NA & 0.01 & NA & NA \\
\hline
\end{tabular}

*Statistically insignificant ( $p>0.05)$.

JOA, Japanese Orthopaedic Association scores; NA, not available; ROM, range of motion; VAS, Visual Analogue Scale scores.

outcomes, the length of hospital stay was similar in both groups, and less blood loss and a shorter operation time were observed in the ACDF group than in the ACCF group. ACDF requires less exposure of the spinal cord than does corpectomy ${ }^{2}$; therefore, less damage to the spinal column occurs. Accordingly, ACDF might result in less blood loss than ACCF. In terms of ACCF, a $15-19 \mathrm{~mm}$ anterior midline trough should be performed in the vertebral body down to the posterior longitudinal ligament or dura, with removal of the cephalad and caudad discs, ${ }^{2}$ which would require more time to be removed; similarly it will cost more time to obtain a graft material to fit the trough. Consequently, ACDF had a significantly shorter operation time.
In our meta-analysis, JOA scores as well as VAS scores for neck and arm pain significantly improved in each group, without significant differences between the two groups. These results suggest that both procedures effectively treat two-adjacent-level CSM and improve the patients' neurological function, quality of life and disability. Similar outcomes were achieved for ACDF and ACCF in the treatment of multilevel cervical spondylosis by Shamji et $a \hat{l}^{3}$ and Jiang $e t a l^{4}$

Total cervical ROM, fusion ROM, fusion rate and adjacent-level ossification yielded no significant differences between the two groups. Concerning the highfusion rate in the two groups, it may be related to the following factors: (1) the use of a polyether ether ketone

A hospital stay

\begin{tabular}{|c|c|c|c|c|c|c|c|c|c|}
\hline \multirow[b]{2}{*}{ Study or Subgroup } & \multicolumn{2}{|c|}{ ACCF } & \multicolumn{3}{|c|}{ ACDF } & \multicolumn{3}{|c|}{ Std. Mean Difference } & \multirow{2}{*}{$\begin{array}{c}\text { Std. Mean Difference } \\
\text { IV. Fixed, } 95 \% \mathrm{CI}\end{array}$} \\
\hline & Mean & SD & Total & Mean & SD & Total & Weight & IV. Fixed, $95 \% \mathrm{Cl}$ & \\
\hline Jia 2012 & 11.11 & 8.52 & 36 & 10.79 & 7.74 & 31 & $46.8 \%$ & $0.04[-0.44,0.52]$ & \\
\hline Liu 2011 & 12.2 & 2.7 & 23 & 11.2 & 2.6 & 23 & $31.7 \%$ & $0.37[-0.21,0.95]$ & \\
\hline Oh 2009 & 16.82 & 7.7 & 17 & 15.14 & 8.5 & 14 & $21.5 \%$ & $0.20[-0.51,0.91]$ & \\
\hline Total $(95 \% \mathrm{Cl})$ & & & 76 & & & 68 & $100.0 \%$ & $0.18[-0.15,0.51]$ & \\
\hline \multicolumn{6}{|c|}{$\begin{array}{l}\text { Heterogeneity: } \text { Chi }^{2}=0.75, d f=2(P=0.69) ; I^{2}=0 \% \\
\text { Test for overall effect: } Z=1.07(P=0.28)\end{array}$} & & & & $\begin{array}{lllll}-1 & -0.5 & 0 & 0.5 & 1 \\
& \text { ACCF } & \text { ACDF }\end{array}$ \\
\hline
\end{tabular}

B bleeding amounts

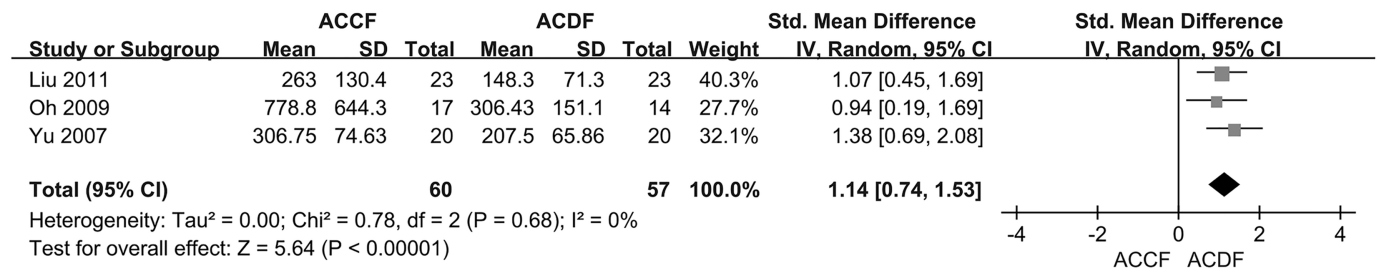

Figure 2 Perioperative parameters. (A) Forest plot and tabulated data for length of hospital stay; no significant difference between the two types of surgery was observed. (B) Forest plot and tabulated data for bleeding amount; the anterior cervical discectomy and fusion group had significantly less intraoperative bleeding than the anterior cervical corpectomy and fusion group. 


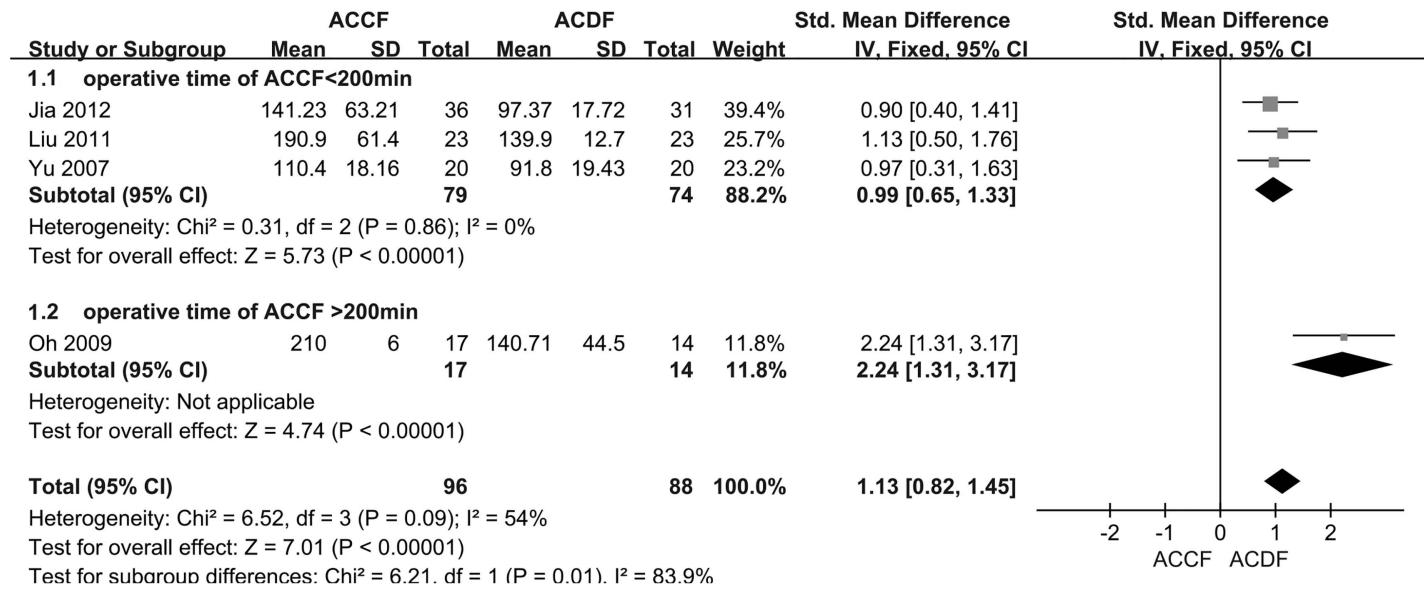

Figure 3 Perioperative parameters. Forest plot and tabulated data for operation time; the anterior cervical discectomy and fusion group had a significantly shorter surgical time compared to the anterior cervical corpectomy and fusion group.

(PEEK) cage or titanium mesh packed with autogenous tricortical bone and fixed by titanium plates and screws or by Atlantis plate fixation ${ }^{9-17}$; (2) the fixation system provides a stable biomechanical environment, which greatly promotes bone healing; and (3) bone healing is a process of creeping substitution, ${ }^{20}$ and the distance of creeping substitution for single-level ACCF and two-level ACDF are short. The high-fusion rate effectively reduced the total cervical and fused segment ROM. For example,
Eck et $a l^{21}$ demonstrated that a significantly greater adjacent level disc pressure was achieved after cervical fusion. In addition, the normal degenerative process plays a major role through impaired nutrition, loss of viable cells, matrix protein modification and matrix failure. $^{22}$ This normal ageing process, in combination with increased mechanical pressures, may synergistically hasten the degeneration process, although it has not been conclusively demonstrated. ${ }^{23}$

A JOA

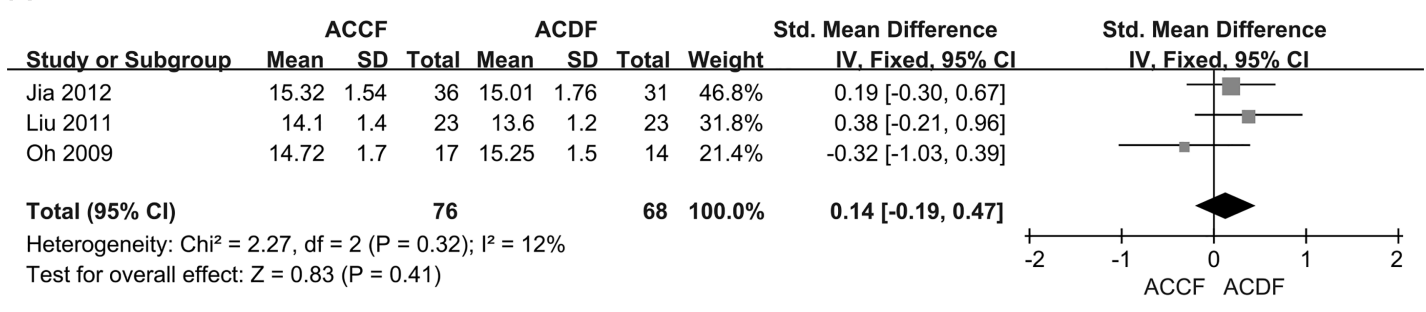

B neck VAS

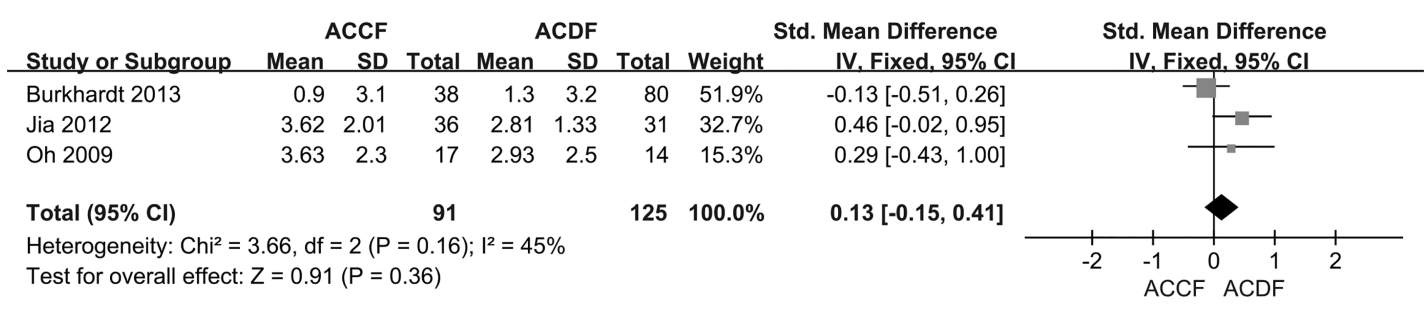

C arm VAS

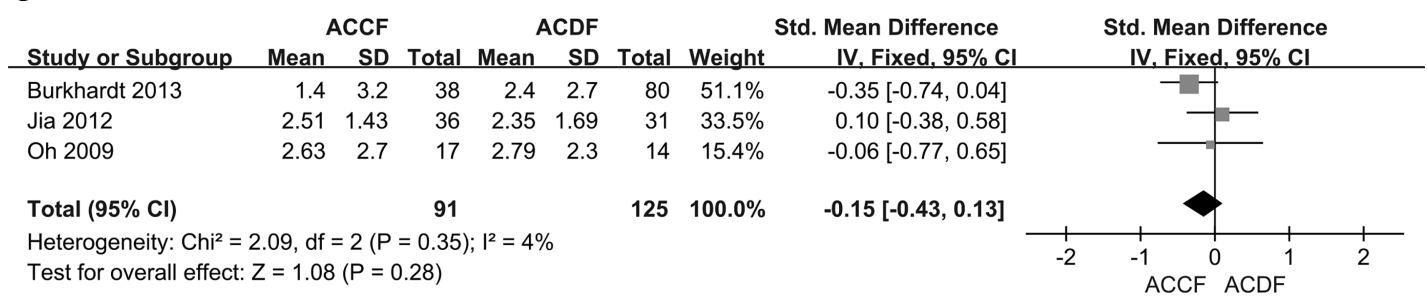

Figure 4 Clinical parameters. (A) Forest plot and tabulated data for the Japanese Orthopaedic Association; (B) Forest plot and tabulated data for the neck visual analogue scale; $(C)$ Forest plot and tabulated data for the arm VAS. There were no significant differences in these parameters between the two types of surgery. 


\section{A C2-C7 Cobb}

\begin{tabular}{|c|c|c|c|c|c|c|c|c|c|}
\hline \multirow[b]{2}{*}{ Study or Subgroup } & \multicolumn{2}{|r|}{$\mathrm{ACCF}$} & \multicolumn{3}{|c|}{ ACDF } & \multirow[b]{2}{*}{ Total } & \multicolumn{2}{|c|}{ Std. Mean Difference } & \multirow{2}{*}{$\begin{array}{c}\text { Std. Mean Difference } \\
\text { IV. Fixed, } 95 \% \mathrm{CI}\end{array}$} \\
\hline & Mean & SD & Total & Mean & SD & & Weight & IV, Fixed, $95 \% \mathrm{Cl}$ & \\
\hline Burkhardt 2013 & 9.7 & 7.7 & 38 & 13.6 & 8.6 & 80 & $29.6 \%$ & $-0.47[-0.86,-0.07]$ & \\
\hline Jia 2012 & 20.26 & 10.26 & 36 & 22.08 & 9.78 & 31 & $19.5 \%$ & $-0.18[-0.66,0.30]$ & \\
\hline Kim 2012 & 15.7 & 8.6 & 16 & 16.7 & 8.5 & 54 & $14.5 \%$ & $-0.12[-0.67,0.44]$ & \\
\hline Oh 2009 & 14.59 & 10.6 & 17 & 23.43 & 7.4 & 14 & $8.1 \%$ & $-0.93[-1.67,-0.18]$ & \\
\hline Park 2010 & 9.6 & 9.1 & 52 & 11.2 & 8.5 & 45 & $28.3 \%$ & $-0.18[-0.58,0.22]$ & \\
\hline Total $(95 \% \mathrm{Cl})$ & & & 159 & & & 224 & $100.0 \%$ & $-0.32[-0.53,-0.10]$ & \\
\hline \multicolumn{6}{|c|}{$\begin{array}{l}\text { Heterogeneity: } \mathrm{Chi}^{2}=4.35, \mathrm{df}=4(P=0.36) ; \mathrm{I}^{2}=8 \% \\
\text { Test for overall effect: } Z=2.90(P=0.004)\end{array}$} & & & & $\begin{array}{llll}-1 & -0.5 & 0 & 0.5 \\
& \text { ACCF } & \text { ACDF }\end{array}$ \\
\hline
\end{tabular}

B fusion Cobb

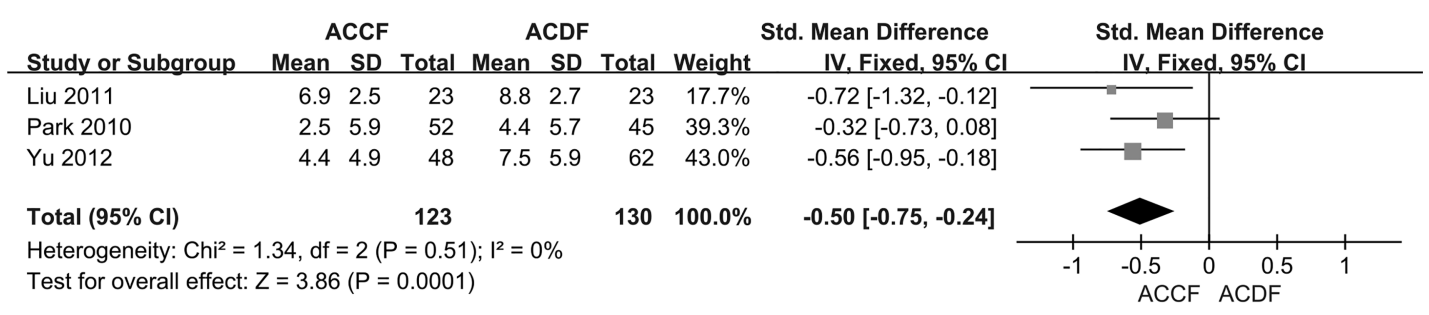

\section{Total cervical ROM}

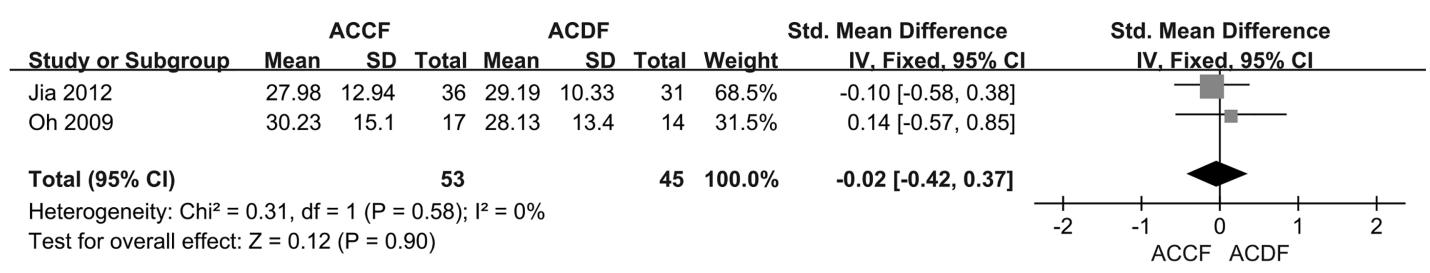

\section{$D$ fusion ROM}

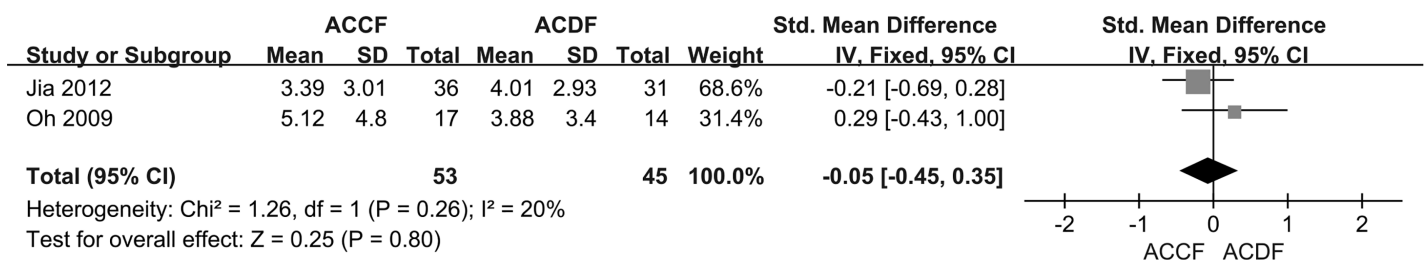

Figure 5 Radiological parameters. (A) Forest plot and tabulated data for C2-C7 Cobb; (B) Forest plot and tabulated data for fusion Cobb; (C) Forest plot and tabulated data for total cervical range of motion (ROM); (D) Forest plot and tabulated data for fusion ROM. The anterior cervical corpectomy and fusion group had a significantly lower Cobb than the anterior cervical discectomy and fusion group. There was no significant difference in the cervical or fusion ROM between the two types of surgery.

For C2-C7 Cobb, ACDF had a significantly greater lordosis angle than ACCF, not only immediately postoperation but also at the final follow-up. Similar results were found for the fusion Cobb at the last follow-up. The reasons may be associated with the following two factors: (1) Single-level ACCF removes the vertebral body and two discs, while two-level ACDF just takes out the two $\operatorname{discs}^{2}$; as a result, ACDF allows the construction of an almost normal spinal column after surgery. Thus, the loss of Cobb is less common in ACDF. In other words, ACDF preserves the sagittal alignment somewhat better than does ACCF. (2) Eck $e t a t^{21}$ have reported that each of the involved joints contributes to the total ROM. With fusion, the contribution of one joint to ROM is reduced.

In terms of the fused segment height, ACCF causes a significant reduction compared to ACDF, both immediately postoperative and at the last follow-up. With ACDF, screws placed in the intervening segment and two caudal end plates synergistically share the load of the construct. In contrast, with a single-level corpectomy, screws are only at the cranial and caudal vertebral segments and the caudal end plate bears the full load of the construct. ${ }^{12}$ Additionally, the graft contact area is less for ACCF than for ACDF, which results in a higher shear stress for ACCF. These reasons might hasten the graft absorption process into the cover plate of the adjacent vertebral body, leading to a significant subsidence of the treated segment in ACCF, especially at the anterior and caudal positions.

Concerning complications, the data show that there is no significant difference between the two groups and that the incidence of complications is low in each group. This result suggests that both the treatments are safe. 
A fused segment height

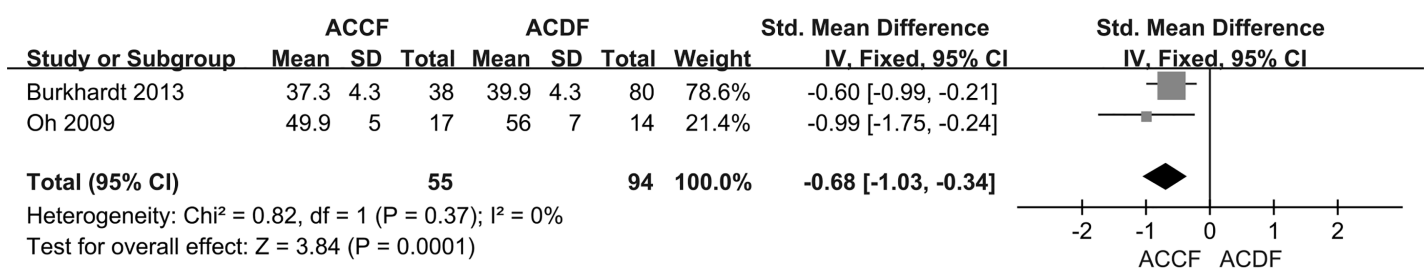

B graft collapse

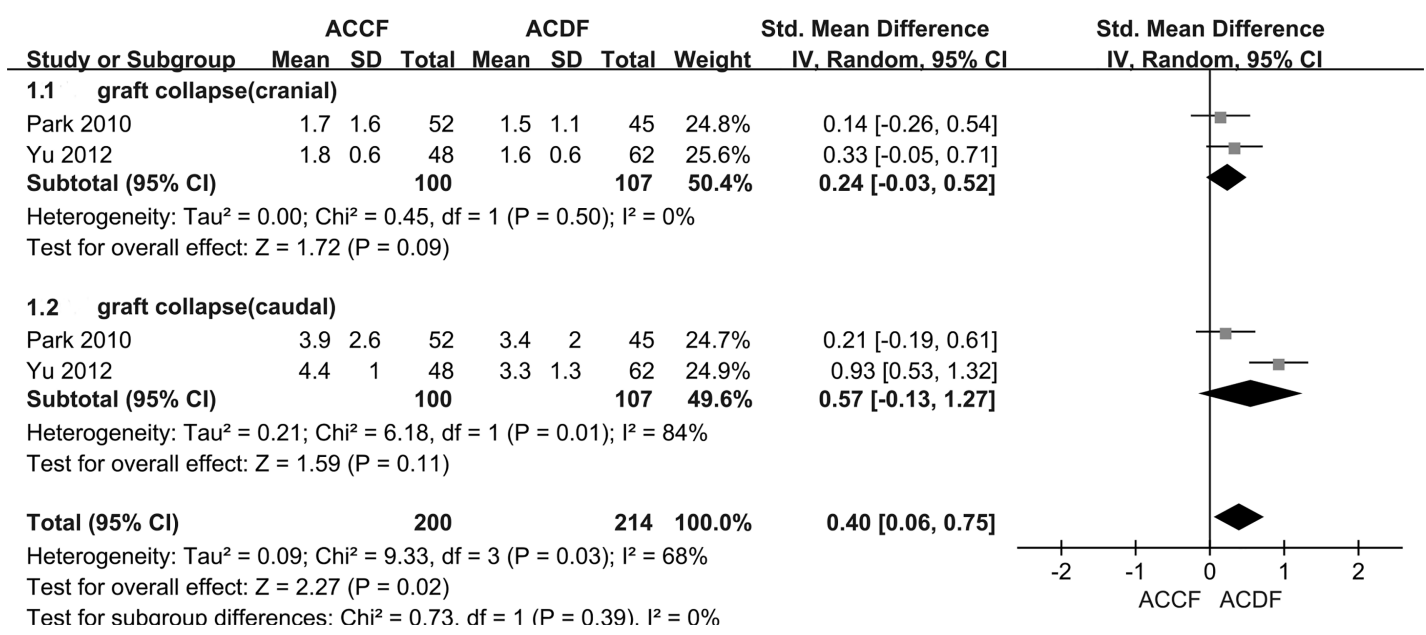

Figure 6 Radiological parameters. (A) Forest plot and tabulated data for the fused segment height; the anterior cervical corpectomy and fusion (ACCF) group had a significantly lower fused segment height than the anterior cervical discectomy and fusion (ACDF) group. (B) Forest plot and tabulated data for graft collapse; the ACDF group had a significantly lower graft collapse than the ACCF group.

The methodological quality assessment should be considered, which identified several limitations of the clinical evidence. Only nine studies met the predefined eligibility criteria, meaning that all the results were based on only 631 patients. More importantly, there were only three studies that were randomised. All randomised studies had poor concealment of randomisation, including selection and allocation bias. Owing to informed consent requirements, patients and operators had knowledge regarding the surgical procedures, thus allowing further measurement and expectation bias. Four outcomes (bleeding amount, operation time, fused segment height and graft collapse) had a high heterogeneity. $\mathrm{Wu}$ et $a l^{24}$ have summarised a method to deal with heterogeneity in meta-analysis. For the bleeding amount, it was reasonable to perform sensitivity analysis (see online supplementary figure S1) because of the different research types. As shown in online supplementary figure $\mathrm{S} 1$, the results of Jia $e a^{16}$ have significant heterogeneity, which should be removed. The bleeding amount results are shown in figure 2B. Regarding the operation time, sensitivity analysis was performed to analyse the data because of the different research types. As shown by the sensitivity analysis results (see online supplementary figure S2), ACDF had a shorter operation time that could not be reversed regardless of which study was removed. Therefore, the heterogeneity did not come from the methodological heterogeneity. Accordingly, there probably exists clinical heterogeneity. Owing to the strict eligibility criteria, the patient data had a good homogeneity; thus, the heterogeneity was due to the ability of the surgeons. The subgroup analysis results regarding operation time are shown in figure 3 . As for the fused segment height, clinical heterogeneity existed. Oh $e t a l^{\theta}$ and Burkhardt $e t a l^{14}$ have defined the fused segment height as the distance between the midlines of the involved cranial vertebral bodies and the caudal vertebral bodies. In contrast, Jia $e t a l^{16}$ did not describe the method to measure the fused segment height. Meanwhile, Liu et $a l^{11}$ and Kim $e t a l^{17}$ reported the anterior and posterior heights of the involved vertebral bodies. In summary, for the fused segment height, we pooled the data of $\mathrm{Oh} e t a t^{9}$ and Burkhardt $e t a l^{14}$ and the outcome is displayed in figure $6 \mathrm{~A}$. With regard to graft collapse, as the two literature examples are both retrospective studies, it is believed that no methodological heterogeneity existed. Regarding the clinical heterogeneity, the patient data had a good homogeneity due to the strict eligibility criteria and the fact that the methods of measuring the graft collapse were the same. 
A fusion rate

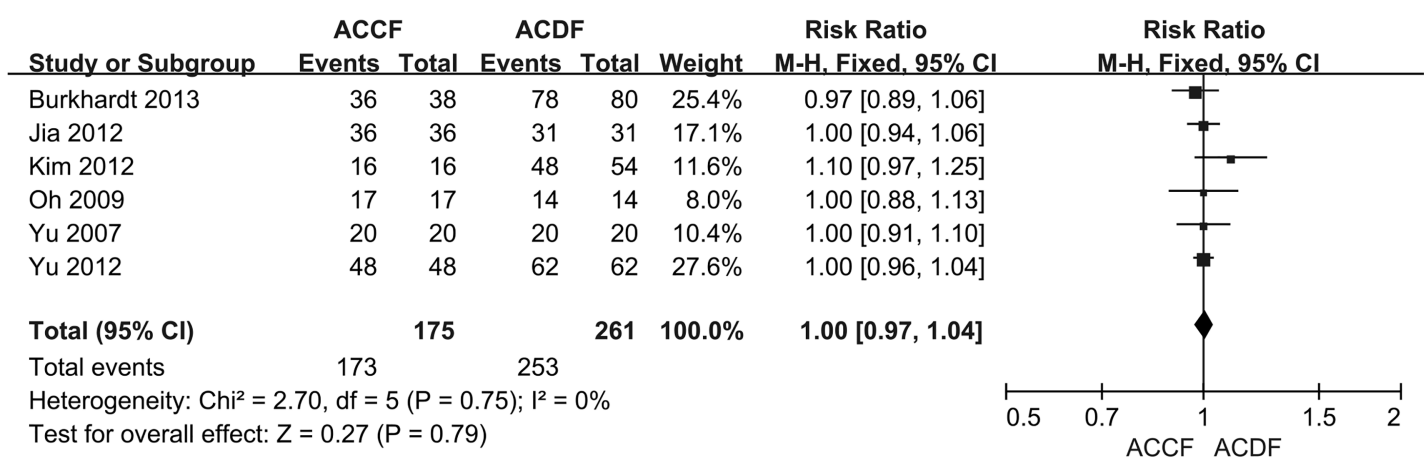

$B$ degeneration of the adjacent-level

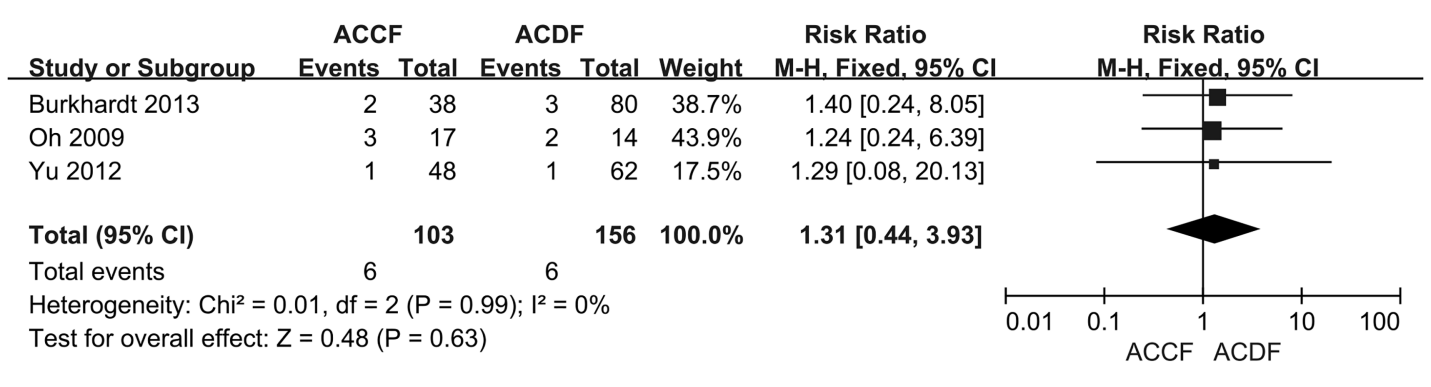

\section{Complications}

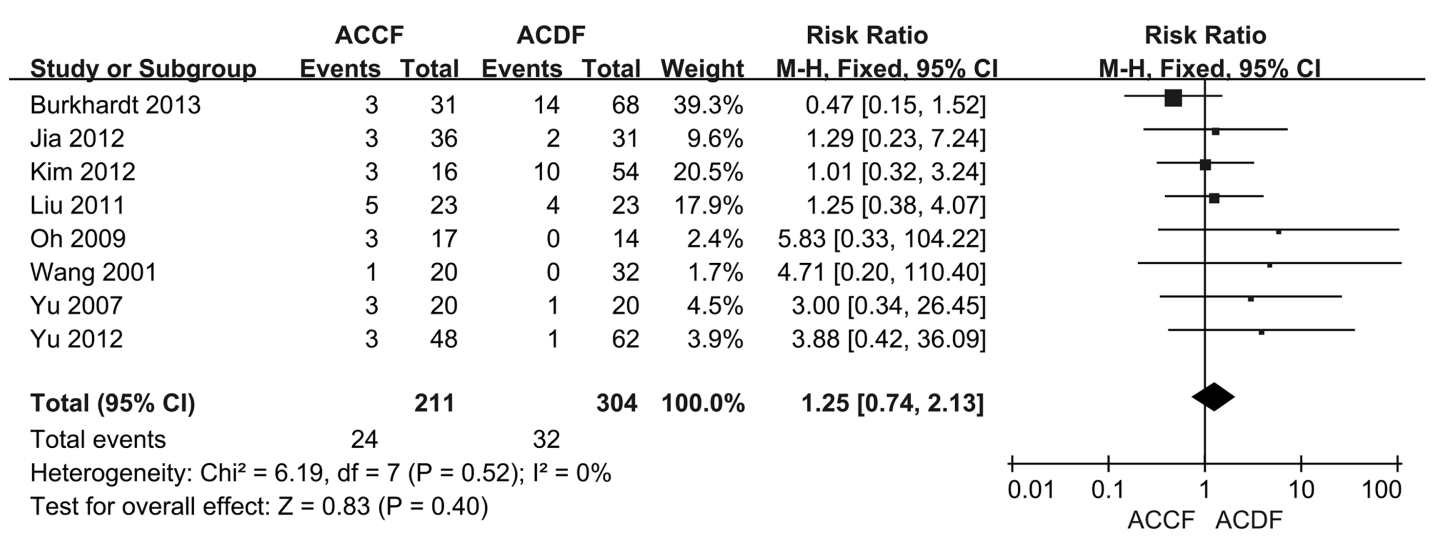

Figure 7 (A) Forest plot and tabulated data for fusion rate; (A) Forest plot and tabulated data for degeneration of the adjacent level; (C) Forest plot and tabulated data for complications. There was no significant difference in any of these parameters between the two types of surgery.

As a result, no significant clinical heterogeneity or methodological heterogeneity was found. However, statistical heterogeneity most likely existed, so the studies were pooled. Not all of the included studies had consistent baseline characteristics between the ACCF and ACDF groups. Therefore, larger randomised controlled trials of high quality are still needed in the future to compare the two surgeries.

\section{CONCLUSION}

Based on this meta-analysis that compared ACDF and ACCF to treat two-adjacent-level CSM, ACDF has some advantages such as less blood loss, a shorter operation time, greater cervical lordosis in the total cervical and fused segments, a higher segmental height and less graft subsidence. However, no significant differences in JOA, VAS, ROM or complications were found. This information will provide surgeons a preliminary understanding of the differences between the two surgeries to treat two-adjacent-level CSM and help clinical surgeons choose the right surgical method to treat patients with two-adjacent-level CSM. Further high-quality RCTs and longer follow-up durations are needed to assess these two treatments.

Acknowledgements The authors thank Medjaden Bioscience for assisting in the preparation of this manuscript.

Contributors Z-YH, A-MW and W-FN conceived and designed the review. Z-YH, A-MW and W-FN performed the review. Z-YH and A-MW analysed the data. Q-LL, TL, K-YW and H-ZX contributed reagents/materials/ analysis tools. Z-YH and A-MW were involved in the writing of the manuscript. 
Funding This work was supported by the Department of Health of Zhejiang Province, Backbone of Talent Project (2012RCB037); and the Department of Science and Technology of Wenzhou, Wenzhou Science and Technology Project (Y20120073).

Competing interests None.

Provenance and peer review Not commissioned; externally peer reviewed.

Data sharing statement No additional data are available.

Open Access This is an Open Access article distributed in accordance with the Creative Commons Attribution Non Commercial (CC BY-NC 3.0) license, which permits others to distribute, remix, adapt, build upon this work noncommercially, and license their derivative works on different terms, provided the original work is properly cited and the use is non-commercial. See: http:// creativecommons.org/licenses/by-nc/3.0/

\section{REFERENCES}

1. King JT Jr, McGinnis KA, Roberts MS, et al. Quality of life assessment with the medical outcomes study short form-36 among patients with cervical spondylotic myelopathy. Neurosurgery 2003;52:113-21.

2. Rao RD, Gourab K, David KS. Operative treatment of cervical spondylotic myelopathy. J Bone Joint Surg Am 2006;88:1619-40.

3. Shamji MF, Massicotte EM, Traynelis VC, et al. Comparison of anterior surgical options for the treatment of multilevel cervical spondylotic myelopathy: a systematic review. Spine 2013;38 (22 Suppl 1):S195-209.

4. Jiang SD, Jiang LS, Dai LY. Anterior cervical discectomy and fusion versus anterior cervical corpectomy and fusion for multilevel cervical spondylosis: a systematic review. Arch Orthop Trauma Surg 2012;132:155-61.

5. Chang WC, Tsou HK, Chen WS, et al. Preliminary comparison of radiolucent cages containing either autogenous cancellous bone or hydroxyapatite graft in multilevel cervical fusion. J Clin Neurosci 2009;16:793-6.

6. Lu J, Wu X, Li Y, et al. Surgical results of anterior corpectomy in the aged patients with cervical myelopathy. Eur Spine J 2008;17:129-35.

7. Yonenobu K, Fuji T, Ono K, et al. Choice of surgical treatment for multisegmental cervical spondylotic myelopathy. Spine 1985;10:710-16.

8. Kawakami M, Tamaki $\mathrm{T}$, Iwasaki $\mathrm{H}$, et al. A comparative study of surgical approaches for cervical compressive myelopathy. Clin Orthop Relat Res 2000;381:129-36.

9. Oh MC, Zhang HY, Park JY, et al. Two-level anterior cervical discectomy versus one-level corpectomy in cervical spondylotic myelopathy. Spine 2009;34:692-6.
10. $\mathrm{Yu} Y-\mathrm{L}$, Gong W-C, Xin B, et al. The comparison of therapeutic efficacy between two operative methods for the treatment of two-adjacent-level CSM. Med Coll J Qiqihaer 2007;28:2821-23.

11. Liu Y, Chen L, Gu Y, et al. Comparison of two anterior decompression bone fusion treatments plus titanium plate implantation for two-level cervical spondylotic myelopathy. J Clin Rehabil Tissue Eng Res 2011;15:597-601.

12. Park $\mathrm{Y}$, Maeda $\mathrm{T}$, Cho W, et al. Comparison of anterior cervical fusion after two-level discectomy or single-level corpectomy: sagittal alignment, cervical lordosis, graft collapse, and adjacent-level ossification. Spine J 2010;10:193-9.

13. Wang JC, McDonough PW, Endow KK, et al. A comparison of fusion rates between single-level cervical corpectomy and two-level discectomy and fusion. J Spinal Disord 2001;14:222-5.

14. Burkhardt JK, Mannion AF, Marbacher S, et al. A comparative effectiveness study of patient-rated and radiographic outcome after 2 types of decompression with fusion for spondylotic myelopathy: anterior cervical discectomy versus corpectomy. Neurosurg Focus 2013;35:E4.

15. Yu F-B, Chen DY, Wang X-W, et al. Radiographic comparison of anterior cervical fusion after two-level discectomy or single-level corpectomy for two-level cervical spondylotic myelopathy. Zhonghua Yi Xue Za Zhi 2012:92:2636-40.

16. Jia X-L, Tan Z-J, Yang F-B, et al. Comparision between single-level cervical corpectomy and two-level discectomy in two-adjacent-level cervical spondylotic myelopathy. Orthop J China 2012;20:1931-4.

17. Kim MK, Kim SM, Jeon KM, et al. Radiographic comparison of four anterior fusion methods in two level cervical disc diseases: autograft plate fixation versus cage plate fixation versus stand-alone cage fusion versus corpectomy and plate fixation. J Korean Neurosurg Soc 2012;51:135-40.

18. Slim K, Nini E, Forestier D, et al. Methodological index for non-randomized studies (minors): development and validation of a new instrument. ANZ J Surg 2003;73:712-16

19. Yin J-H, Zhou Z-H, Chen J. On the combined calculation of the average, the standard deviation and the passing rate of various small samples. J Zhaotong Teach Coll 2010;32:61-4

20. Isaksson $\mathrm{H}$, Wilson W, van Donkelaar CC, et al. Comparison of biophysical stimuli for mechano-regulation of tissue differentiation during fracture healing. J Biomech 2006;39:1507-16.

21. Eck JC, Humphreys SC, Lim TH, et al. Biomechanical study on the effect of cervical spine fusion on adjacent-level intradiscal pressure and segmental motion. Spine 2002;27:2431-4.

22. Buckwalter JA. Spine update aging and degeneration of the human intervertebral disc. Spine 1995;20:1307-14.

23. Hwang SH, Kayanja M, Milks RA, et al. Biomechanical comparison of adjacent segmental motion after ventral cervical fixation with varying angles of lordosis. Spine $J$ 2007;7:216-21.

24. Wu T-X, Liu G-J, Li J. Some risk of affecting the quality of published systematic reviews. Chin J Evid Based Med 2005;5:51-8. 